\title{
Lack of Association between NYD-SP18 Variant and Obesity. The Health Alcohol and Psychosocial Factors in Eastern Europe Study
}

\author{
Jaroslav A. Hubacek ${ }^{a}$ Hynek Pikhart $^{c}$ Ruzena Kubinova ${ }^{b}$ Anne Peasey \\ Sofia Malyutinad Andrzej Pajak ${ }^{\mathrm{e}}$ Abdonas Tamosiunas $^{f}$ Martin Bobak $^{\mathrm{c}}$ \\ ${ }^{a}$ Center for Experimental Medicine, Institute for Clinical and Experimental Medicine, ${ }^{b}$ Centre for Health Monitoring, \\ National Institute of Public Health, Prague, Czech Republic; ' Department of Epidemiology and Public Health, \\ University College London, London, UK; ${ }^{d}$ Institute of Internal and Preventive Medicine, Russian Academy of Medical

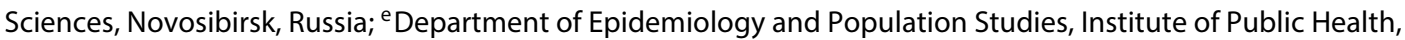 \\ Faculty of Health Care, Jagiellonian University Medical College, Krakow, Poland; ' Department of Population Studies, \\ Institute of Cardiology of Lithuanian University of Health Sciences, Kaunas, Lithuania
}

\section{Key Words}

NYD-SP18 · Polymorphism · Obesity · Body mass index ·

Waist-hip ratio $\cdot$ FTO $\cdot$ Energy intake

\begin{abstract}
Aim: To replicate the finding that the polymorphism rs6971091 within the NYD-SP18 gene is associated with body mass index (BMI). Method: We analysed data of 29,284 adults (46.2\% of males, mean age 58.9 (SD 7.3), mean BMI 28.6 (5.0 $\left.\mathrm{kg} / \mathrm{m}^{2}\right)$ ) examined within the Health Alcohol and Psychosocial Factors in Eastern Europe study in the Czech Republic, Poland, Lithuania and Russia. Results: BMI did not differ by rs6971091 genotype. In men, the mean BMI (SEs) in GG, GA and AA carriers were $27.8(0.05), 27.9(0.06)$ and $27.9(0.14)$ $\mathrm{kg} / \mathrm{m}^{2}$, respectively, $(\mathrm{p}=0.26)$; in women, the corresponding values were 29.2 (0.06), 29.1 (0.07) and 29.1 (0.16), $p=0.57$. In Czech subjects $(n=6,752)$, for whom the FTO rs 17817449 genotype was available, there was no interaction between the NYD-SP18 and FTO polymorphisms in determination of BMI. Adjustment for age, energy and fat intake and physical activity did not materially change the results. There was no
\end{abstract}

association of the NYD-SP18 genotype with waist-hip ratio. Conclusion: This study in a large Slavonic population sample suggests that the rs6971091 variant within the NYD-SP18 gene is not an important determinant of obesity in middleaged persons.

(C) 2016 The Author(s) Published by S. Karger AG, Basel

\section{Introduction}

Obesity is a common preventable risk factor of a range of chronic conditions, including cardiovascular diseases, cancer and diabetes. In some populations, as much as $60 \%$ of individuals are overweight or obese [1]. Obesity or overweight generally results from positive energy balance caused predominantly by low physical activity and high energy intake, although other factors, such as sleeping deficit or social factors also play a role [2]. In addition to these environmental factors, obesity and body mass index (BMI) are significantly influenced by genetic factors. Twin studies suggest that genetic influences may explain as much as $40-70 \%$ of the variation in BMI [3]. 
However, despite intensive research efforts in the last decades, only a relatively small part of the BMI heritability has been attributed to specific genetic factors.

Among the polymorphisms with known association with obesity, the most important are the FTO 1st intron variants [4]. The study based on the NHLBI Family Heart Study and the Framingham study identified a single nucleotide polymorphism (rs697109) within the NYD-SP18 gene (gene ID 84691) as associated with obesity [5]. The gene was identified using fine mapping of the region on chromosome 7, which has been known for a long time to be associated with obesity [6]. The authors reported an effect of the NYD-SP18 variants on obesity that was even larger than the effect of the FTO polymorphism [5]. More recently, the association between the rs697109 SNP and BMI was confirmed in males, but not in females [7]. In addition, the additive effect between this SNP and 1st intron polymorphism of the FTO gene on BMI values has been detected [7]. Finally, a small intervention study in females suggested that NYD-SP18 polymorphism could be a significant predictor of positive body composition changes after a short-term intensive life style intervention [8].

The NYD-SP18 gene is known to play a role in the development of testicles (Locus ID 84691), but the mechanisms that may link it with obesity development are not known. Rs6971091 is a non-synonymous polymorphism ( $\mathrm{G}>\mathrm{A}$; Lys242>Glu), and it was predicted that it could cause the misfolding of the native protein (http://snpeffect.vib.be/snp_main.php?id=27249604) [9].

To the best of our knowledge, the effect of the rs6971091 SNP on obesity has not been independently replicated in a different population sample. The aim of this study is to test the replicability of the previously described association between the rs6971091 SNP within the NYD-SP18 gene and obesity-associated traits.

\section{Subjects and Methods}

We analysed data from 4 large population-based cohorts of adults established as part of the Health Alcohol and Psychosocial Factors in Eastern Europe (HAPIEE) study in the Czech Republic, Lithuania, Poland and Russia [10]. The cohorts consist of random samples of both men and women aged 45-69 (45-75 in Lithuania) at baseline. Subjects were selected from population registers; no exclusion criteria have been applied.

Dietary intakes of energy and macro- and micro-nutrients were assessed by 143-items Food Frequency Questionnaire as described previously $[11,12]$. Physical activity was assessed by questions asking how many hours per week the responders engaged in sports, games or hiking. The socioeconomic status was characterised by participants' highest achieved education and the economic activities they were involved in [10].

All subjects provided a written informed consent to participate in the study. The study was approved by appropriate institutional Ethics Committees in agreement with the Helsinki Declaration of 1975.

DNA was extracted from the peripheral blood and NYD-SP18 SNP rs6971091 was genotyped using the KASPTM methodology (KBioscience, London, England) [13]. Genotyping call rate was $97.98 \%$. Both in the entire study $(\mathrm{p}=0.77)$ and within each of the 4 populations, there was no evidence of deviation from the HardyWeinberg equilibrium. Means and SEs of BMI and waist-to-hip ratio (WHR) were estimated by linear regression post-estimation of adjusted means. STATA statistical software (version 12) was used for all analyses. Age, energy intake, fat intake, physical activity, education and socioeconomic status were included in adjusted analysis. $p$ values (calculated for trend) $<0.05$ were considered significant.

\section{Results}

Descriptive characteristics of study participants are shown in table 1 . There were only minor differences between countries. For instance, Lithuanians had the highest mean age and the highest mean BMI (both p values $<0.001$ ). The genotype (allele) distributions were similar across the countries; the overall allele distribution (with minor A allele frequency of $26 \%$ ) were also similar to the distribution reported previously (frequency of the minor allele $23 \%)[5,7]$. In our study, both overall and within each cohort, the rs6971091 polymorphism was not associated with BMI values; all $p$ values were $>0.45$ in codominant models (table 1). The results remain insignificant after adjustment for age and other covariates and in dominant and recessive models. Results of WHR were similar; the mean (SEs) of WHR in males with GG, GA and AA genotypes were $0.943(0.001), 0.943(0.001)$ and 0.945 (0.002), respectively, with $\mathrm{p}=0.432$; in females, the corresponding values were $0.834(0.001), 0.838(0.001)$ and 0.835 (0.002), respectively, with $\mathrm{p}=0.814$.

We have not detected any significant interaction between energy intake and NYD-SP18 polymorphism in predicting BMI, either in the combined male and female population or when males and females were analysed separately. We did not find any associations of this variant with total dietary intake of energy or saturated and unsaturated fats.

Finally, in the Czech cohort $(n=6,752)$, where data on FTO rs17817449 genotype were available [14], we examined an interaction between FTO and NYD-SP18 genotypes (table 2). While FTO was strongly associated with BMI (as reported earlier [14]), there was no suggestion of 
Table 1. Basic characteristics of subjects with successful NYD-SP18 genotyping

\begin{tabular}{|c|c|c|c|c|c|}
\hline Country & Czech Republic & Lithuania & Poland & Russia & Total \\
\hline Number & 6,725 & 6,828 & 8,742 & 6,989 & 29,284 \\
\hline Males, \% & 46.0 & 46.0 & 49.0 & 43.1 & 46.2 \\
\hline $\mathrm{BMI}, \mathrm{kg} / \mathrm{m}^{2}$ & $28.2 \pm 4.6$ & $29.3 \pm 5.3$ & $28.2 \pm 4.6$ & $28.6 \pm 5.4$ & $28.6 \pm 5.0$ \\
\hline WHR & $0.886 \pm 0.085$ & $0.894 \pm 0.087$ & $0.880 \pm 0.083$ & $0.888 \pm 0.087$ & $0.886 \pm 0.085$ \\
\hline AG & $2,582(38.5)$ & $2,645(38.9)$ & $3,482(39.8)$ & $2,703(38.7)$ & $11,412(39.0)$ \\
\hline AA & $471(7.0)$ & $486(7.1)$ & $601(6.9)$ & $480(6.9)$ & $2,038(7.0)$ \\
\hline \multicolumn{6}{|c|}{ BMI by rs6971091 NYD-SP18 in men } \\
\hline GG & $28.2 \pm 0.1$ & $28.5 \pm 0.1$ & $27.9 \pm 0.1$ & $26.6 \pm 0.1$ & $27.8 \pm 0.05$ \\
\hline GA & $28.5 \pm 0.1$ & $28.5 \pm 0.1$ & $28.0 \pm 0.1$ & $26.5 \pm 0.1$ & $27.9 \pm 0.06$ \\
\hline $\mathrm{AA}$ & $28.0 \pm 0.3$ & $28.9 \pm 0.3$ & $27.9 \pm 0.2$ & $27.0 \pm 0.3$ & $27.9 \pm 0.14$ \\
\hline $\mathrm{AA}$ & $27.7 \pm 0.3$ & $30.1 \pm 0.3$ & $28.4 \pm 0.3$ & $30.2 \pm 0.3$ & $29.1 \pm 0.16$ \\
\hline $\mathrm{p}$ value & 0.67 & 0.49 & 0.67 & 0.67 & 0.57 \\
\hline
\end{tabular}

Genotype frequency is given as $\mathrm{n}(\%), \mathrm{BMI}$ values are reported as mean $\pm \mathrm{SE}$. Linear regression.

Table 2. BMI values (mean \pm SEs) of by the combination of FTO (rs17817449) and NYD-SP18 (rs6971091) polymorphisms in Czech subjects (both genders combined)

\begin{tabular}{lccccc}
\hline NYD-SP18 genotype & \multicolumn{2}{l}{ FTO genotype } & \multirow{2}{*}{ p for trend } \\
\cline { 2 - 5 } & GG & GT & TT & total & \\
\hline GG & $28.6 \pm 0.2$ & $28.3 \pm 0.1$ & $27.8 \pm 0.1$ & $28.2 \pm 0.1$ & $<0.001$ \\
GA & $28.8 \pm 0.2$ & $28.3 \pm 0.1$ & $28.0 \pm 0.2$ & $28.3 \pm 0.1$ & 0.002 \\
AA & $28.7 \pm 0.5$ & $28.0 \pm 0.3$ & $27.3 \pm 0.3$ & $27.9 \pm 0.2$ & 0.016 \\
Total & $28.7 \pm 0.1$ & $28.3 \pm 0.1$ & $27.8 \pm 0.1$ & $28.2 \pm 0.1$ & $<0.001$ \\
p for trend & 0.458 & 0.434 & 0.851 & 0.828 & $0.662^{*}$ \\
\hline
\end{tabular}

Mean BMI are reported as mean \pm SE. Linear regression.

$* \mathrm{p}$ for interaction $=0.662$.

an association between FTO and NYD-SP18 polymorphisms $(\mathrm{p}=0.323)$ or of an interaction between these 2 genotypes in determining BMI $(\mathrm{p}=0.664)$ or WHR $(\mathrm{p}=$ 0.564 , not shown in the table 2 ).

\section{Discussion}

Genome-wide association studies and the deep sequencing of areas with high logarithm of odds score for obesity have detected dozens of SNPs with the potential to significantly affect BMI. However, many of the associations detected in the primary studies remain unconfirmed. It is important that results from even large genetic association studies are replicated in independent population samples [15]; the reasons include statistical issues (to exclude false positive findings), possible interethnic differences and potential modification of genetic effects by environmental and life style factors.

There is a wide list of genes/variants potentially associated with BMI or other indicators of obesity; however, definitive conclusions are sometimes difficult to be drawn 
[16-22]. Importantly, not all genetic variants are associated with BMI under all conditions in all population, as is the case of FTO [23]. For several genotypes, it has been reported that dietary and genetics factors may interact with one another (e.g. variants at $M C 4 r$ [24], APOA5 [25] or TFAP2B [26]).

In the case of the promising candidate, SNPs within the NYD-SP18 gene area, the potential physiological link between this gene and obesity remain unknown; however, this applies to some extent to most obesity-associated genes (such as TMEM18 or FTO). In the original report [5], it was suggested that NYD-SP18 polymorphism may influence plasma leptin levels.

The primary report [5] found the association with obesity in two independent population samples; however, the relatively small sample size in these studies (several hundred individuals in each sample) makes them prone to false positive results. More recently, the association has been detected in males, but not in females, in the Czech post-MONICA study [7]. The possible role of the NYDSP18 in the determination of BMI has been further suggested in a small intervention study [8] of overweight non-diabetic females; the results suggest that common homozygotes profit more from the intensive life style intervention than carriers of the minor A allele.

Our study, with almost 30,000 unrelated adults, was much larger. We have found not even a slight suggestion of a trend in BMI by NYD-SP18. In addition, in a subset of 6,500 individuals, we found no evidence of interactions with the FTO genotype or dietary intakes energy or fats.

There is one major limitation of our study, which can potentially explain the difference between the previous reports $[5,7]$ and our study. Both previous papers $[5,7]$ also included younger individuals, while the HAPIEE study only covers persons aged 45 years or older. We, therefore, cannot exclude the possibility that an association between the NYD-SP18 genotype and BMI exists in younger age groups. However, given the results of this large study, we conclude that the rs6971091 SNP within the NYD-SP18 gene is unlikely to be an important genetic determinant of BMI per se.

\section{Disclosure Statement}

All authors declare no conflict of interest.

\section{Acknowledgements}

The HAPIEE study was supported by the Wellcome Trust, the US National Institute of Aging, by the Russian Scientific Foundation (grant no. 14-45-00030), and by the project (Ministry of Health, Czech Republic) for development of research organization 00023001 (Institute for Clinical and Experimental Medicine, Prague, Czech Republic) - institutional support.

\section{References}

1 Berghöfer A, Pischon T, Reinhold T, Apovian CM, Sharma AM, Willich SN: Obesity prevalence from a European perspective: a systematic review. BMC Public Health 2008;8:200.

2 Hubácek JA: Eat less and exercise more - is it really enough to knock down the obesity pandemia? Physiol Res 2009;58(suppl 1):S1-S6.

3 Day FR, Loos RJ: Developments in obesity genetics in the era of genome-wide association studies. J Nutrigenet Nutrigenomics 2011;4: 222-238.

4 Fawcett KA, Barroso I: The genetics of obesity: FTO leads the way. Trends Genet 2010; 26:266-274.

5 Wilk JB, Laramie JM, Latourelle JC, Williamson S, Nagle MW, Tobin JE, Foster CL, Eckfeldt JH, Province MA, Borecki IB, Myers RH: NYD-SP18 is associated with obesity in the NHLBI family heart study. Int J Obes (Lond) 2008;32:930-935.

6 Feitosa MF, Borecki IB, Rich SS, Arnett DK, Sholinsky P, Myers RH, Leppert M, Province MA: Quantitative-trait loci influencing bodymass index reside on chromosomes 7 and 13 : the national heart, lung, and blood institute family heart study. Am J Hum Genet 2002;70: $72-82$.

7 Hubacek JA, Dlouha D, Lanska V, Adamkova $\mathrm{V}$ : Strong gender-specific additive effects of the NYD-SP18 and FTO variants on BMI values. Physiol Res 2015;64(suppl 3):S419-S426.

8 Suchánek P, Lánská V, Hubáček JA: Body composition changes in adult females after lifestyle intervention are influenced by the NYD-SP18 variant. Cent Eur J Public Health 2015;23(suppl):S19-S22.

9 Reumers J, Conde L, Medina I, Maurer-Stroh S, Van Durme J, Dopazo J, Rousseau F, Schymkowitz J: Joint annotation of coding and non-coding single nucleotide polymorphisms and mutations in the SNPeffect and PupaSuite databases. Nucleic Acids Res 2008; 36:D825-D829.

10 Peasey A, Bobak M, Kubinova R, Malyutina S Pajak A, Tamosiunas A, Pikhart H, Nicholson A, Marmot M: Determinants of cardiovascular disease and other non-communicable diseases in Central and Eastern Europe: rationale and design of the HAPIEE study. BMC Public Health 2006;6:255.

11 Willett WC, Sampson L, Stampfer MJ, Rosner B, Bain C, Witschi J, Hennekens CH, Speizer FE: Reproducibility and validity of a semiquantitative food frequency questionnaire. Am J Epidemiol 1985;122:51-65.

12 Brunner E, Stallone D, Juneja M, Bingham S, Marmot M: Dietary assessment in Whitehall II: comparison of $7 \mathrm{~d}$ diet dairy and food-frequency questionnaire and validity against biomarkers. Br J Nutr 2001;86:405-414.

13 Hubáček JA, Pikhart H, Peasey A, Kubínová R, Bobák M: Nobody is perfect: comparison of the accuracy of PCR-RFLP and KASPTM method for genotyping. ADH1B and FTO polymorphisms as examples. Folia Biol (Praha) 2015;61:156-160.

14 Hubacek JA, Bohuslavova R, Kuthanova L, Kubinova R, Peasey A, Pikhart $\mathrm{H}$, Marmot MG, Bobak M: The FTO gene and obesity in a large Eastern European population sample: the HAPIEE study. Obesity (Silver Spring) 2008;16:2764-2766. 
15 Munafò MR: Reliability and replicability of genetic association studies. Addiction 2009; 104:1439-1440.

16 Mansoori A, Amini M, Kolahdooz F, Seyedrezazadeh E: Obesity and Pro12Ala polymorphism of peroxisome proliferator-activated receptor-gamma gene in healthy adults: a systematic review and meta-analysis. Ann Nutr Metab 2015;67:104-118.

17 Yeo GS: The role of the FTO (fat mass and obesity related) locus in regulating body size and composition. Mol Cell Endocrinol 2014; 397:34-41.

18 Zhang L, Yuan LH, Xiao Y, Lu MY, Zhang LJ, Wang Y: Association of leptin gene $-2548 \mathrm{G} / \mathrm{A}$ polymorphism with obesity: a meta-analysis. Ann Nutr Metab 2014;64: 127-136.

19 Tang L, Ye H, Hong Q, Chen F, Wang Q, Xu L, Bu S, Liu Q, Ye M, Wang DW, Mai Y, Duan S: Meta-analyses between 18 candidate genetic markers and overweight/obesity. Diagn Pathol 2014;9:56.

20 Fujiwara CT, Edna de Melo M, Corrêa Mancini M: Association of leptin gene -2548 G/A polymorphism with obesity: a meta-analysis. Ann Nutr Metab 2015;66:109.

21 Speakman JR: Functional analysis of seven genes linked to body mass index and adipos- ity by genome-wide association studies: a review. Hum Hered 2013;75:57-79.

22 Fall T, Ingelsson E: Genome-wide association studies of obesity and metabolic syndrome. Mol Cell Endocrinol 2014;382:740-757.

23 Qi Q, Kilpeläinen TO, Downer MK, Tanaka T, Smith CE, Sluijs I, Sonestedt E, Chu AY, Renström F, Lin X, Ängquist LH, Huang J, Liu Z, Li Y, Asif Ali M, Xu M, Ahluwalia TS, Boer JM, Chen P, Daimon M, Eriksson J, Perola M, Friedlander Y, Gao YT, Heppe DH, Holloway JW, Houston DK, Kanoni S, Kim YM, Laaksonen MA, Jääskeläinen T, Lee NR, Lehtimäki T, Lemaitre RN, Lu W, Luben RN, Manichaikul A, Männistö S, Marques-Vidal $P$, Monda KL, Ngwa JS, Perusse L, van Rooij FJ, Xiang YB, Wen W, Wojczynski MK, Zhu J, Borecki IB, Bouchard C, Cai Q, Cooper C, Dedoussis GV, Deloukas P, Ferrucci L, Forouhi NG, Hansen T, Christiansen L, Hofman A, Johansson I, Jørgensen T, Karasawa S, Khaw KT, Kim MK, Kristiansson K, Li H, Lin X, Liu Y, Lohman KK, Long J, Mikkilä V, Mozaffarian D, North K, Pedersen O, Raitakari O, Rissanen $\mathrm{H}$, Tuomilehto J, van der Schouw YT, Uitterlinden AG, Zillikens MC, Franco OH, Shyong Tai E, Ou Shu X, Siscovick DS, Toft U, Verschuren WM, Vollenweider P, Wareham NJ, Witteman JC, Zheng W, Ridker PM,
Kang JH, Liang L, Jensen MK, Curhan GC Pasquale LR, Hunter DJ, Mohlke KL, Uusitupa M, Cupples LA, Rankinen T, Orho-Melander M, Wang T, Chasman DI, Franks PW, Sørensen TI, Hu FB, Loos RJ, Nettleton JA, Q1 L: FTO genetic variants, dietary intake and body mass index: insights from 177,330 individuals. Hum Mol Genet 2014;23:6961-6972.

24 Koochakpoor G, Hosseini-Esfahani F, Daneshpour MS, Hosseini SA, Mirmiran P: Effect of interactions of polymorphisms in the melanocortin-4 receptor gene with dietary factors on the risk of obesity and type 2 diabetes: a systematic review. Diabet Med 2015, Epub ahead of print.

25 Lim HH, Choi M, Kim JY, Lee JH, Kim OY: Increased risk of obesity related to total energy intake with the APOA5-1131T > C polymorphism in Korean premenopausal women. Nutr Res 2014;34:827-836.

26 Stocks T, Angquist L, Banasik K, Harder MN, Taylor MA, Hager J, Arner P, Oppert JM, Martinez JA, Polak J, Rousseau F, Langin D, Rössner S, Holst C, MacDonald IA, Kamatani Y, Pfeiffer AF, Kunesova M, Saris WH, Hansen T, Pedersen O, Astrup A, Sørensen TI: TFAP2B influences the effect of dietary fat on weight loss under energy restriction. PLoS One 2012;7:e43212. 